\title{
Alexithymia, Psychopathology and Alcohol Misuse in Adolescence: A Population Based Study on 3556 Teenagers
}

\author{
Michela Gatta $^{1 *}$, Irene Facca ${ }^{1}$, Elena Colombo ${ }^{1}$, Lorenza Svanellini ${ }^{1}$, Sara Montagnese ${ }^{2}$, \\ Sami Schiff ${ }^{2}$ \\ ${ }^{1}$ Woman and Child Care Department, Padua University Hospital, Padua, Italy \\ ${ }^{2}$ Department of Medicine, Padua University Hospital, Padua, Italy \\ Email: ${ }^{*}$ michela.gatta@unipd.it
}

Received 7 February 2014; revised 1 March 2014; accepted 20 March 2014

Copyright @ 2014 by authors and Scientific Research Publishing Inc.

This work is licensed under the Creative Commons Attribution International License (CC BY). http://creativecommons.org/licenses/by/4.0/

(c) (i) Open Access

\begin{abstract}
Objectives: To analyze the association between alexithymia and alcohol intake during adolescence, also in relation to psychopathology, in order to identify psychological risk factors for alcohol misuse. Method: 3556 students [mean age (range) 14.5 years $(11-18)]$ were recruited in the Padua area. Each was administered a set of three questionnaires: the Toronto Alexithymia Scale for children (TAS-20) to measure alexithymia, the Questionnaire Adolescent Saturday evening (QAS) to estimate of alcohol intake, and the Youth Self-Report (YSR 11 - 18) to value psychopathology. Results: Externalizing problems appeared to increase with age and with the amount of alcohol consumed, unlike internalizing problems. The prevalence of alexithymia was $18 \%$, decreasing with age, and it was not associated with alcohol consumption, and used except in younger subjects ( $\leq 13)$, for whom a positive correlation was observed between alexithymia, internalizing problems and alcohol intake. Conclusions: Younger adolescents are more psycho-emotionally vulnerable (internalizing problems and alexithymia) and at a greater risk of alcohol misuse.
\end{abstract}

\section{Keywords}

Alexithymia; Alcohol; Adolescence; Psychopathology

\section{Introduction}

Epidemiological evidence indicates that alcohol is the most commonly used and misused substance amongst

${ }^{*}$ Corresponding author.

How to cite this paper: Gatta, M., Facca, I., Colombo, E., Svanellini, L., Montagnese, S. and Schiff, S. (2014) Alexithymia, Psychopathology and Alcohol Misuse in Adolescence: A Population Based Study on 3556 Teenagers. Neuroscience \& Medicine, 5, 60-71. http://dx.doi.org/10.4236/nm.2014.51009 
adolescents. Alcohol consumption has both biological and psycho-social consequences, impinging on both personal growth and the subsequent transition to adulthood.

In large-scale study conducted in the USA [1], 8\% of adolescents between the ages of 12 and 17 were found to meet the DSM-IV-TR [2] criteria for the diagnosis of alcohol misuse/addiction to alcohol, and the figure raises to $21 \%$ between the ages of 18 and 25 .

Over the last ten years, alcohol consumption amongst Italian adolescents seems to have been stable, with a higher prevalence in the Central-Northern regions, especially the North-East and particularly among males (83.0\% vs. $64.6 \%$ in females) [3] [4]. The behavior of habitual consumers has changed significantly from regular wine consumption over meals to "binge-drinking". This pattern of consumption, which is already widespread in the United States [5] [6] and in Northern European countries, has been consolidating among young people, increasing from $15.4 \%$ to $18.9 \%$ in the age group 14 - 17 between 1999 and 2009. Binge-drinking remains more common in males (18\% to $20.4 \%$ increase), but has increased to a greater extent in females (12.8\% to $17.4 \%)$ [4]. Furthermore, adolescents are drinking for the first time at a younger age, most commonly at 13 [4]. All these issues suggest that prevention programmes to reduce alcohol intake amongst young people and delay their first contact with alcohol are badly needed. Moreover, behavioral responses to heavy drinking also include risk-taking behavior, which may harm the drinker and others as a result of drunken driving, road traffic accidents, unprotected sexual intercourse, violent or criminal behavior [1]. The psychopathological and behavioral fallout is also relevant, although it is often not taken into and thus underestimated. More attention is usually paid to the physical consequences, but the psychological and behavioral consequences or alcohol misuse are actually more frequent and possibly more important in young people: indeed, frequent consumption of alcohol in adolescence is associated with conduct disorders [7] [8], Attention Deficit Hyperactivity Disorder (ADHD), drug misuse, attempted suicide [9], and mood disorders, especially depression, anxiety, bulimia, and schizophrenia [10].

Psychopathological aspects related to alcohol misuse have been investigated also in adults: several studies have shown an association between alcoholism and a cognitive affective disorder termed alexithymia. Alexithymia is characterized by: 1) difficulties in discriminating between emotions and bodily sensation; 2) difficulty in communicating emotions to others verbally; 3) limited imaginative processes; 4) an externally oriented cognitive style [11]. The prevalence of alexithymia in adult alcohol misusers is $45 \%$ - 67\% [12]-[15]. Since alexithymic individuals often feel uncomfortable in social situations [15] [16], some researchers have suggested that in these subjects, alcohol misuse might be a coping strategy, helping to deal with stress or improve interpersonal functioning [17] [18]. Thus alexithymia may be a risk factor for the development of alcohol misuse [11] [19]-[21].

The prevalence of alexithymia in adolescents has been analyzed too: $10 \%$ in girls and $7 \%$ in boys, but with a higher average value (i.e. more pronounced alexithymia) in males compared to females [22] [23]. Then, the prevalence was similar to that of adults, but without relevant gender difference (in adults alexithymia is more common in males instead). Anyway, the relationship between alcohol misuse and alexithymia in adolescents has not been studied yet. The aim of our study was to analyze the association, if any, between alexithymia and alcohol intake in adolescence, the working hypothesis being that higher alcohol intake would be associated with more pronounced alexithymia traits, as observed in adults. In addition, on the basis of literature which found an association between alexithymia and psychopathology (internalizing problems-like anxiety, somatisation, withdrawal and depression, and externalizing ones-like aggressiveness) [24], we examined the presence of emotional and behavioural problems associated with alexithymia in order to better understand psychological risk factors for alcohol use/misuse at a young age, in order to potentially direct more specific preventive interventions.

\section{Methods}

\subsection{Participants}

The study was performed on a sample of 3556 students from 30 schools in Padua (15 middle schools and 15 high schools), who had joined the initiative called "Education for health and the prevention of early alcohol consumption in adolescence and preadolescence" during the 2010-2011 school year. This project was organized, beginning in 2006, with the cooperation of several public health and social services agencies, together with the University of Padua and the Veneto Region (the Padua University Child and Adolescent Psychiatry Unit, the Social Services at the ULSS 16 Padua, the Regional Center for Liver Diseases at Padua the University Hospital, 
the Venetian Regional Education Office, the Rotary Club in Padua, the Fondazione Lionello Forin Hepatos ONLUS) [25]. The project was designed for students attending middle and high schools and, alongside its preventive goals, it included a research effort to identify variables related to drinking in adolescence (protective and risk factors), with a view to gaining a better understanding of the phenomenon and the factors behind it, as reported in various other our studies [26]-[29].

The $67 \%$ of the sample (2387 students) attended high school and the remaining 33\% (1169 students) attended middle school. The mean age was 14.5 years. 1874 students (53\%) were male and 1653 (46\%) female (about 1\% did not provide answers).

\subsection{Procedures}

All the students were administered the 20-item Toronto Alexithymia Scale (TAS-20) [30] and a questionnaire on how they spent their Saturday evenings (QAS) [31] to assess alexithymia and alcohol consumption, respectively. Any emotional-behavioral issues were assessed with Achenbach's Youth Self-Report (YSR 11-18) [32] only for the high school students, because some middle-school teachers refused to administer the YSR 11-18, considering it "too demanding" for this age group. Questionnaires were administered by a trained psychologist in the second week of October 2010. This date was chosen because it is far away from any public holidays or particular events that might prompt an unusual alcohol consumption, so the situation on any typical Saturday evening could be investigated. Questionnaires were kept anonymous by using acronyms. Informed verbal consent to the students' participation was required first from the school directors, then from all parents, and from each student enrolled. None of the parents or students refused. The study was conducted in full compliance with the Padua General Hospital's ethical principles (Deliberation of the Ethical Committee, dated 13.02.2012).

\subsection{Questionnaires}

Three questionnaires were administered: the Questionnaire Adolescents Saturday night evening (QAS) [33], the TAS-20 for children [30] and the Youth Self-Report [32].

\subsubsection{The Questionnaire on Adolescents' Saturday Evenings (QAS)}

The Questionnaire on Adolescents Saturday evenings (QAS) consists of questions with multiple-choice answers, and it was prepared by the Padua University Hospital Department of Clinical Toxicology and Drug Dependence to explore the consumption of recreational drinks, both alcoholic and non-alcoholic, over the previous Saturday evening (intended as the hours between dinner and bed time). In addition, information was also collected on socio-demographic conditions, weekly availability of money, social context, time of returning home, type and amount of alcoholic units ( 1 unit $=12 \mathrm{gr}$ of ethanol, e.g. a small glass of wine, a can of beer or a shot of spirits) [34].

\subsubsection{The Toronto Alexithymia Scale-20 Items}

The TAS-20 is a self-report questionnaire that measures the three defining factors of alexithymia: "difficulty in identifying feelings", "difficulty in communicating feelings to others", "externally oriented thinking”. It allows to classify subjects into non-alexithymic (scores < 51), borderline (scores 51 - 60), or alexithymic (scores > 61). In our study, we utilised the TAS-20 for developmental age, translated and validated from the version of Rieffe, Oosterveld and Terwogt (2006) [35], which has simplified the TAS-20 for adults, and validated by Di Trani et al. (2009) [30].

\subsubsection{The Youth Self-Report}

The YSR 11-18 [32] is one of the most commonly-used scales for rating juvenile behavior both in the clinical and research setting. It has been translated and validated in its Italian version [36] [37]. The questionnaire yields two profiles: one for competences (activities, social functioning, school performance), the other for behavior and emotions, which can be qualified as "normal", "borderline" or "clinical" on 8 specific syndrome scales: anxiety/depression, withdrawal, somatization, social problems, thought-related problems, attention problems, aggressive and role-breaking behavior. In turn, these are grouped into: internalizing problems (anxiety, depression and withdrawal, somatization); externalizing problems (aggressive and role-breaking behavior); and other problems (social, thought-related, attention). 


\subsection{Data Analysis}

Data were entered into a database (EXCEL) and processed using the statistical software Statistica (version 7.1). Descriptive statistics were used to assess the socio-demographic and clinical characteristics of the sample, and their relationship with the frequency/amount of alcohol consumption (chi-squares and unpaired t-tests, respectively). One-way, factorial and repeated measures ANOVA was utilized to assess alexithymia. Values were considered significant if $\mathrm{p}<0.05$.

\section{Results}

\subsection{Alcohol Consumption}

1191 subjects (33.5\%) reported consumption of at least one alcohol unit on the Saturday before the interview. Alcohol consumption was more common in males: $40.6 \%$ vs. $26 \%$. Alcohol consumption increased with age, from $10.6 \%$ in middle schools to $44.7 \%$ in high school (Table 1 ).

\subsection{Psycho-Behavioural Profiles}

A higher prevalence of externalizing (22.5\%) than internalizing problems (14.9\%) was observed.

Externalizing problems increased with chronological age, unlike internalizing problems, which seemed more stable; in addition, externalizing problems increased in parallel with alcohol consumption, while internalizing problems do not show a statistically significant relationship with the consumption of alcohol (Figures 1 and 2).

\subsection{Alexithymia}

The prevalence of alexithymia in our sample was $18 \%$ (27\% if borderline subjects were included), and it decreased with age (Table 2 and Figure 3).

In the sub-sample of the subjects who had consumed alcohol on the previous Saturday night (qualified as "drinkers"), we found that alexithymia decreased with the increase in alcohol consumption (which, in turn, increased with age), but drinkers and non-drinkers had comparable alexithymia scores. Thus alexithymia does not seem to be related to alcohol consumption but it seems to be more closely related to age (Table 3).

However, a relationship was observed between alexithymia and alcohol consumption in younger drinkers $(\leq 13)$ : these had higher scores in the TAS 20 compared to their non-drinkers peers, and this finding was more pronounced for the Identification subscale (Figures 4 and 5 ).

In further detail, in this age group $(\leq 13)$, a significant association was detected between alexithymia and alcohol consumption: the younger subjects with issues related to alexithymic identificatory component, drink more than their non-alexthymic peers $(F(29,902)=2.2497, \mathrm{p}=0.00020)$. This association was not found in older age groups, in which drinkers and non-drinkers reported similar alexithymia scores.

Besides, in the subsample of subject that performed YSR and TAS 20, we found that subjects younger than 13 years reported higher scores on internalizing problems than their non-drinking peers $([\mathrm{F}(4,114)=4.2599, \mathrm{p}=$ $0.00300)$. A significant linear correlation between alexithymia and internalizing problems was also observed $(\mathrm{r}=$ 0.37) (Figure 6).

\section{Discussion}

Our research on alexithymia, psychopathology, and alcohol consumption in adolescence confirmed some results already emerged from recent research on the topic [1] [6] [22]-[24] [38] and it added new information that can guide in the future a wider intervention in terms of both prevention and research.

\subsection{Prevalence of Alcohol Consumption and of Behavioral Problems}

With regard to alcohol consumption, this was shown to be more common in males than females, both in middle and high schools, as previously observed in recent Italian [3] [4] and international surveys [1] [5] [6]. Alcohol consumption was also shown to increase with age, in agreement with previous studies [1] [3] [5] [6].

The observed prevalence of internalizing and externalizing problems differs from that reported in previous Italian studies [39] [40] for higher prevalence values and for the more frequent presence of externalizing problems compared to internalizing ones. However, Levi et al. (2009) [40] observed subjects aged 11 - 14 years old; 
Table 1. Alcohol consumption by gender and school grade (frequencies and percentages).

\begin{tabular}{cccccccc}
\hline & Males (n) & Females (n) & Not specified & Total & Males (\%) & Females (\%) & Total (\%) \\
\hline Middle school & 90 & 33 & 1 & 124 & 14.8 & 6.0 & $\mathbf{1 0 . 6}$ \\
High school & 671 & 396 & 0 & 1067 & 53.0 & 35.8 & $\mathbf{4 4 . 7}$ \\
Total & 761 & 429 & 1 & 1191 & 40.6 & 26.0 & 33.5 \\
\hline
\end{tabular}

Table 2. Alexithymia in subjects who filled TAS 20 in (frequencies and percentages).

\begin{tabular}{ccccc}
\hline Alexithymia & Normal & Borderline & Clinical & Total \\
\hline Frequencies & 886 & 445 & 297 & 1628 \\
Percentages (\%) & 55 & 27 & 18 & 100 \\
\hline
\end{tabular}

Table 3. Alexithymia in drinkers students, by alcohol consumption (Alcohol Units - AU: $<3,3-4, \geq 5$ ) (frequencies and percentages).

\begin{tabular}{|c|c|c|c|c|}
\hline \multirow[b]{2}{*}{ Consumed Alcoholic Units } & \multicolumn{4}{|c|}{ Alexithymia } \\
\hline & Normal & Borderline & Clinical & Total \\
\hline $\mathbf{A U}<\mathbf{3}$ & 146 & 65 & 45 & 256 \\
\hline AU 3 - 4 & 39 & 25 & 7 & 71 \\
\hline $\mathbf{A} \mathbf{U} \geq \mathbf{5}$ & 52 & 18 & 8 & 78 \\
\hline Total (n) & 237 & 108 & 60 & 405 \\
\hline $\mathrm{AU}<3(\%)$ & 36.0 & 16.0 & 11.1 & 63.1 \\
\hline AU 3 - $4(\%)$ & 9.6 & 6.2 & 1.7 & 17.6 \\
\hline$A U \geq 5(\%)$ & 12.8 & 4.4 & 2.0 & 19.3 \\
\hline Total (\%) & 58.5 & 26.7 & 14.8 & 100 \\
\hline
\end{tabular}

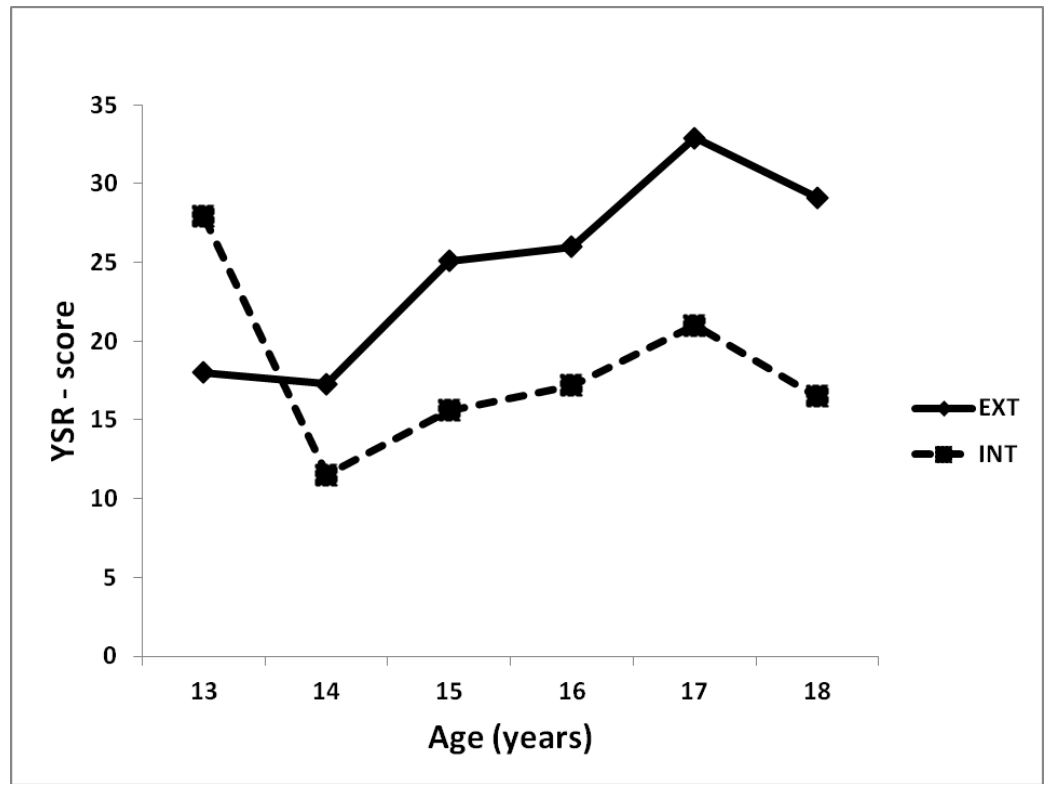

Figure 1. Internalizing (INT) and externalizing (EXT) problems' trend by age in high school students. 


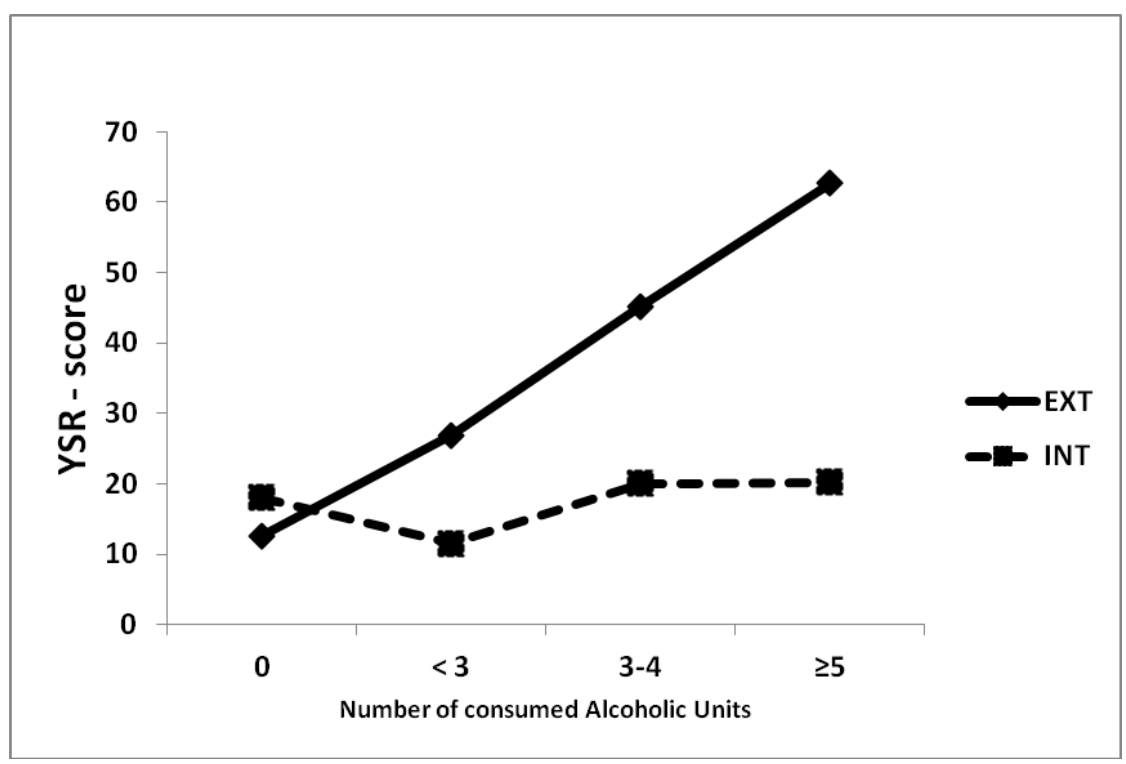

Figure 2. Internalizing (INT) and externalizing (EXT) problems' scores in high school students according to alcohol consumption (numbers of Alcohol Units (AU): 0, 1 - 2, 3 $4, \geq 5)$.

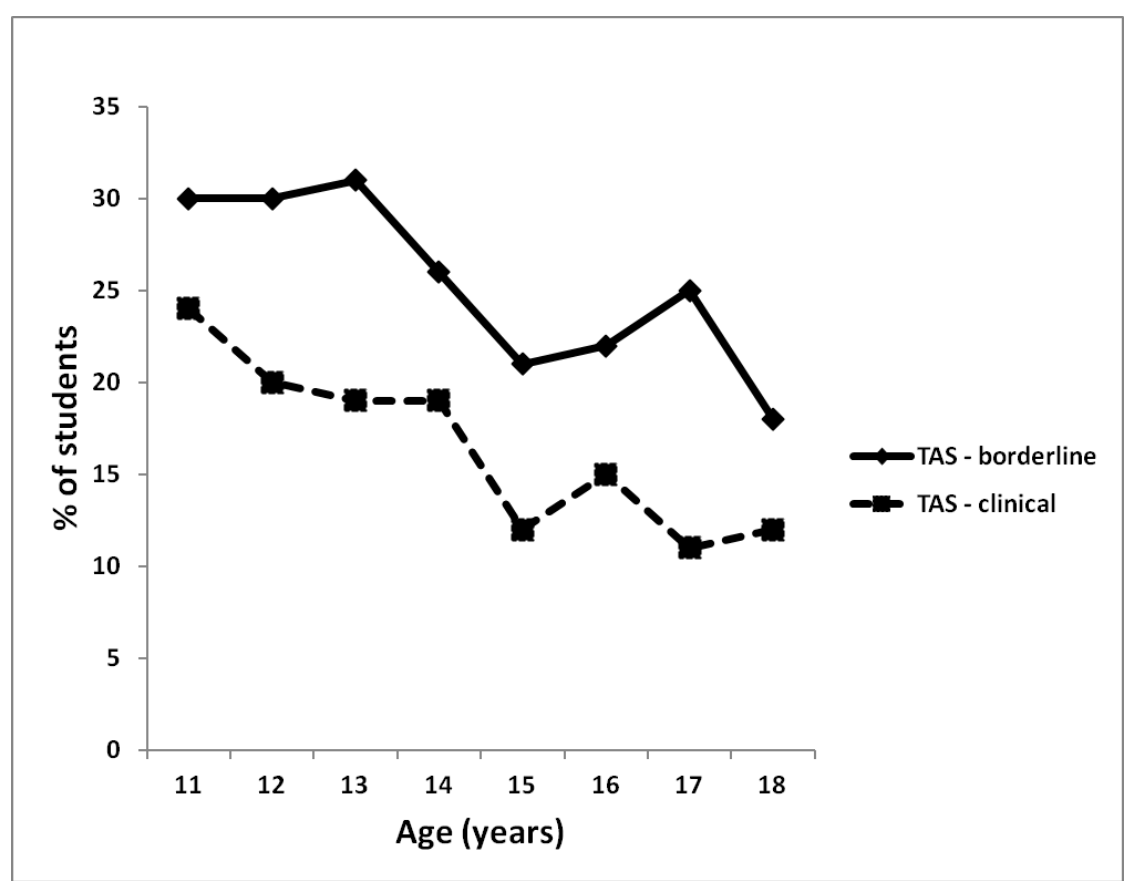

Figure 3. Percentage of students by age, with TAS scores compatible with borderline and clinical alexithymia.

it is well known that the percentage of psychopathological risk increases with age [41], therefore the differences between our data (14 - 18 years old) and the literature ones is most likely to relate to age differences in the samples. In our research, externalizing problems increased with age, unlike internalizing ones, which were more stable. In contrast, an extensive study on adolescents from 12 countries [42] showed that the scores for externalizing problems, obtained with the YSR, decreased with age, while internalizing problems underwent an increase. However, the age range was 6 - 17 years, and the countries considered included Australia, China, Thailand and Jamaica. Thus age and geographical/cultural differences may account for differences in the results. 


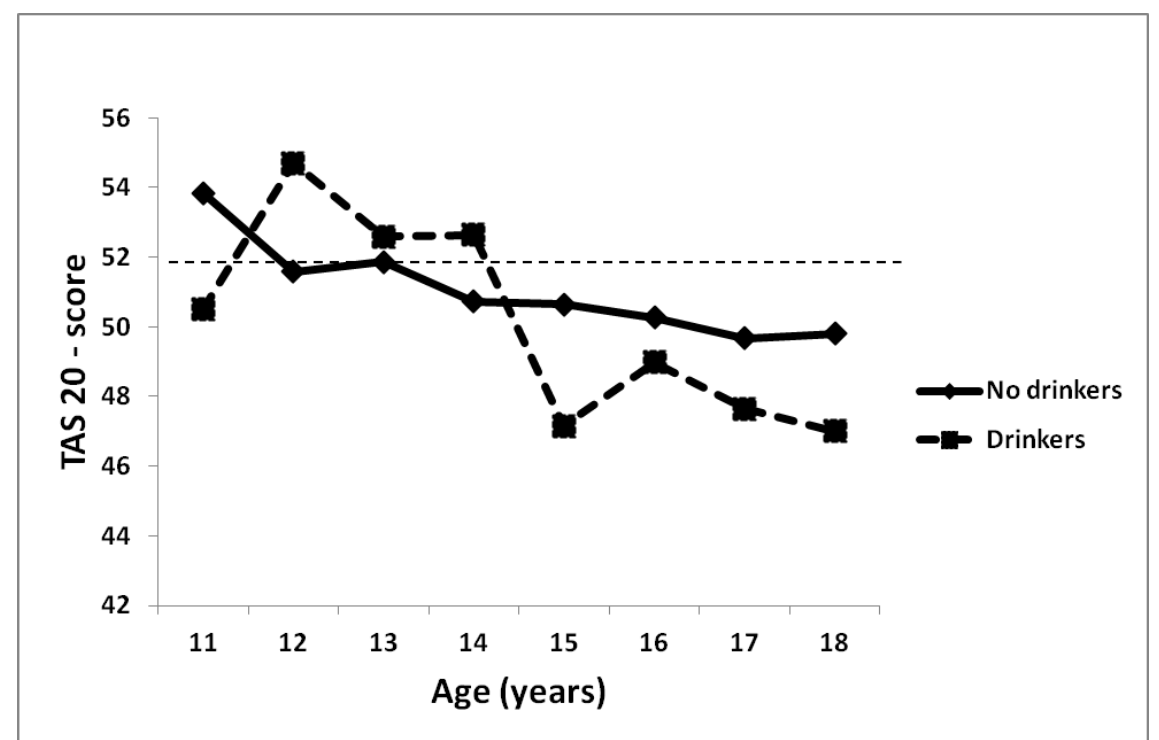

Figure 4. Alexithymia by age and alcohol consumption. Horizontal line represents the cut off for borderline/clinical values of alexithymia.

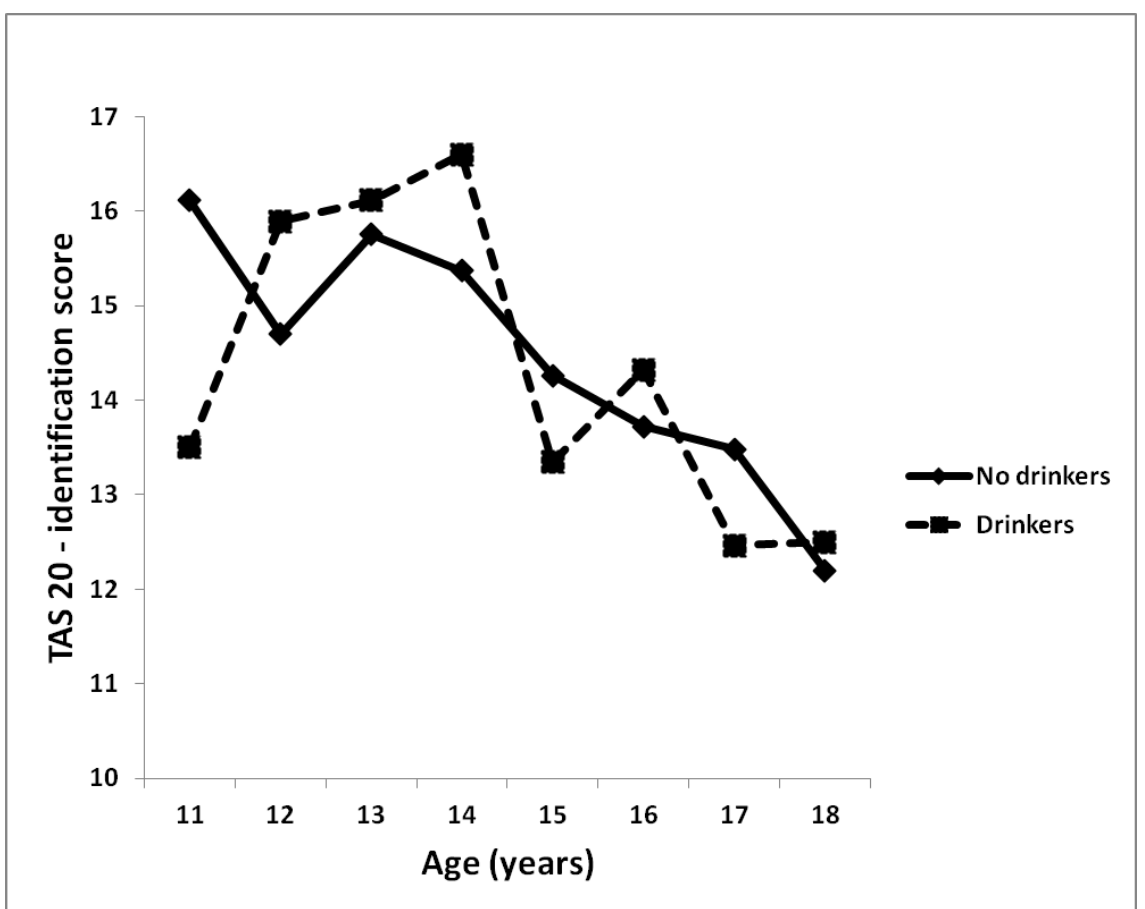

Figure 5. Identification subscale (Alexithymia F1) by age and alcohol consumption.

\subsection{Relationship between Alcohol Consumption and Behavioral Problems}

In our study, the externalizing problems correlated with alcohol use, unlike the internalizing ones, which did not show a significant statistical relationship with alcohol consumption. This trend is confirmed by other studies in this area [1]; in particular, Vanheusden et al. (2008) [38] found that heavy drinkers amongst young adults had a higher prevalence of externalizing problems. Other studies examined the relationship between high alcohol use in children and externalizing problems, particularly delinquency [8] [43], and linked high consumption of alcohol in late adolescence with externalizing problems, such as the tendency to rebellion [44], the difficulty to avoid damaging or harmful situations [45] and traits of disinhibition [46] [47]. 


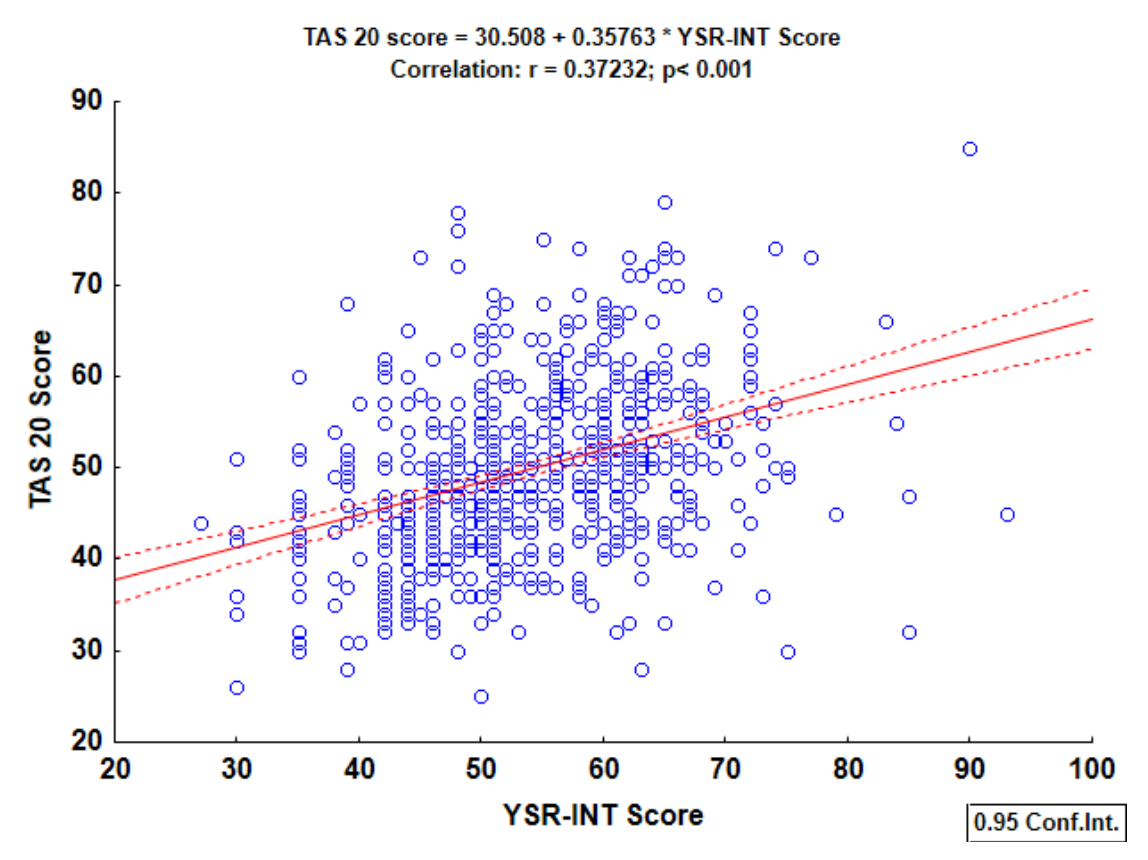

Figure 6. Correlation between alexithymia and internalizing problems.

Although in literature studies about the correlation between externalizing problems and alcohol use in adolescence are more common [43] [48]-[53], it must be said that some studies suggest the presence of a correlation between internalizing problems and use of alcohol [48] [50] [53] in adolescents like in adults [54]. Young people with disruptive or overactive-aggressive behavior, often referred to as "antisocial", or young people who are depressed, withdrawn and anxious may be at increased risk of consuming alcohol [55]. However, further research on the subject is necessary, given the limited amount of data available on this issue, especially in adolescence.

\subsection{Alexithymia, Behavioral Problems and Alcohol Consumption}

In our sample, the prevalence of alexithymia was higher (18\%) than that found in other studies of adolescents [22]-[24], but the latter ones investigated older subjects.

In the sample as a whole, there was a linear correlation between alexithymia and internalizing problems, confirming the literature data, such as the study of Honkalampi et al., (2009) [24] which shows a strong correlation between alexithymia (in particular the subscale of "Identification") and internalizing problems in adolescents.

Regarding the relationship between alcohol consumption and alexithymia we had no data to compare because in the literature there are no previous studies analyzing this relationship. The fact that alexithymia's scores decrease with the increase of age in the total sample tested (drinkers and non-drinkers) is consistent with the gradual improvement of cognitive abilities related to the control of emotional response, and confirms similar findings in other studies [24]. In contrast to our initial hypothesis, in the subsample of drinkers we found that alexithymia decreased with the increase in alcohol consumption. This is a finding that differs from the results of investigations on the relationship between alexithymia and alcoholism conducted in adults, a context in which several researches have reported higher rates of alexithymia in alcoholics, between $45 \%$ and $67 \%$ [12]-[15] [17] [18] [56] [57].

In view of the data mentioned above, we analyzed whether the decrease in the TAS-20 scores with the increase in alcohol consumption had a meaning in itself or was mediated by the relationship between age and alexithymia. Since drinkers and non-drinkers reported similar scores for alexithymia, it does not seem to be related to the amount of alcohol consumed. The trend of alexithymia in the total sample seems more closely related to age than alcohol consumption, suggesting that the latter association is a reflection of the correlation between age and alcohol consumption.

The lack of a relationship between alexithymia and alcohol consumption was not confirmed in young drinkers ( $\leq 13$ years); the interesting and completely new finding is that subjects with high scores in the TAS-20 (indicat- 
ing a higher level of alexithymia), compared with their non-alexithymic peers, were more prone to alcohol consumption. In the age group $\leq 13$, a significant association between alexithymia (especially the identificatory component) and alcohol consumption was observed, unlike what happens in elder groups. Moreover, in this particular age group, the subsample of drinkers obtained higher scores on internalizing problems compared to their non-drinkers peers. These results support the hypothesis that alexithymia is a risk factor for alcohol misuse rather than its sequel [11] [17]-[20] [58].

\section{Conclusion}

Based on our findings, it can be hypothesized that younger students, who are more vulnerable from a psychobehavioral point of view (internalizing problems and alexithymia) are at greater risk of alcohol misuse. In contrast, in older students, the socio-cultural risk factors [3], such as the influence of peers (the most powerful predictor of alcohol consumption in adolescence) and expectations on the socializing and positive aspects of alcohol [59] could play a major role. In these age groups (from mid-adolescence onwards), the presence of psychobehavioral problems (which appears associated with alcohol consumption and older age) may be one of the consequences of alcohol abuse or at least a concomitant expression of "phase specific" distress with potential development into psychopathology. Further research should investigate and confirm these preliminary results.

\section{Acknowledgements}

We thank Rotary Club of Padua and Fondazione Hepathos L. Forin for promoting and organizing this research project.

\section{References}

[1] Substance Abuse and Mental Health Services Administration SAMSHA (2009) Results from the 2008 National Survey on Drug Use and Health: National Findings. Office of Applied Studies, Rockville.

[2] American Psychological Association (1994) Diagnostic and Statistical Manual of Mental Disorders, 4th (DSM-IV). American Psychological Association, Washington DC.

[3] Arcidiacono, C. and Caianiello, E. (2008) Nuovi stili di consumo alcolico negli adolescenti italiani: Allarme sociale al Nord e fenomeno invisibile al Sud. Statistica e Società, 5, 1-3.

[4] Istituto Nazionale di Statistica ISTAT (2010) Indagine Multiscopo sulle Famiglie: Aspetti della vita quotidiana. Anno 2008, Roma.

[5] Johnston, L.D., O’Malley, P.M., Bachman, J.G. and Schulenberg, J.E. (2010a) Monitoring the Future National Results on Adolescents Drug Use: Overview of Key Findings, 2007. National Institute on Drug Abuse, Bethesda.

[6] Johnston, L.D., O’Malley, P.M., Bachman, J.G. and Schulenberg, J.E. (2010b) Monitoring the Future National Survey Results on Drug Use 1975-2009: Volume I, Secondary School Students. National Institute on Drug Abuse, Bethesda,

[7] Boyle, M.H. and Offord, D.R. (1991) Psychiatric Disorders and Substance Use in Adolescence. Canadian Journal of Psychiatry, 36, 699-705.

[8] Niemela, S.M., Sourander, A., Poikolainen, K., Elonheimo, H., Heleniuis, H., Sillanmoki, L., Multimaki, P. and Parkkola, K. (2006) Adaptive Functioning, Psychopathology and Service among 18-Years-Old Boys with DrunkennessRelated Alcohol Use. Alcohol, 41, 143-150. http://dx.doi.org/10.1093/alcalc/agh261

[9] Windle, M., Spear, P., Fuligni, A.J., Angold, A., Brown, J.D., Pine, D., Smith, G.T., Giedd, J. and Dahl, R.E. (2008) Transitions into Underage and Problem Drinking: Developmental Processes and Mechanisms between 10 and 15 Years of Age. Pediatrics, 121, 273-289. http://dx.doi.org/10.1542/peds.2007-2243C

[10] Simkin, D. (2002) Adolescent Substance Use Disorders and Comorbidity. Pediatric Clinics of North America, 49, 463477. http://dx.doi.org/10.1016/S0031-3955(01)00014-1

[11] Taylor, G.J., Bagby, R.M. and Parker, J.D.A. (1997) Disorders of Affect Regulation. Alexithymia in Medical and Psychiatric Illness. Cambridge University Press, Cambridge. http://dx.doi.org/10.1017/CBO9780511526831

[12] Evren, C., Kose, S., Sayar, K., Ozcelik, B., Borckardt, J.P., Elhai, J.D. and Cloninger, R.C. (2008) Alexithymia and Temperament and Character Model of Personality in Alcohol-Dependent Turkish Men. Psychiatry and Clinical Neurosciences, 64, 371-378. http://dx.doi.org/10.1111/j.1440-1819.2008.01829.x

[13] Loas, G., Fremaux, D., Otmani, O., Lecercle, C. and Delahousse, J. (1997) Is Alexithymia a Negative Factor for Maintaining Abstinence? A Follow Up-Study. Comprehensive Psychiatry, 38, 296-299.

http://dx.doi.org/10.1016/S0010-440X(97)90063-8 
[14] Sauvage, L. and Loas, G. (2006) Criterion Validity of Bermond-Vorst Alexithymia Questionnaire-20 Form B: A Study of 63 Alcoholic Subjects. Psychological Reports, 98, 234-236. http://dx.doi.org/10.2466/pr0.98.1.234-236

[15] Uzun, A.Z., Ates, A., Cansever, A. and Ozsahin, A. (2003) Alexithymia in Male Alcoholics: Study in a Turkish Sample. Comprehensive Psychiatry, 44, 349-352. http://dx.doi.org/10.1016/S0010-440X(03)00009-9

[16] Wise, T.N., Mann, L.S. and Shay, L. (1992) Alexithymia and the Five-Factor Model of Personality. Comprehensive Psychiatry, 33, 147-151. http://dx.doi.org/10.1016/0010-440X(92)90023-J

[17] Kauhanen, J., Julkunen, J. and Salonen, J.T. (1992) Coping with Inner Feelings and Stress: Heavy Alcohol Use in the Context of Alexithymia. Behavioral Medicine, 18, 121-126. http://dx.doi.org/10.1080/08964289.1992.9936962

[18] Rybakowki, J., Ziolkowski, M., Zasadska, T. and Brzezinski, R. (1988) High Prevalence of Alexithymia in Male Patients with Alcohol Dependence. Drug and Alcohol Dependence, 21, 133-136. http://dx.doi.org/10.1016/0376-8716(88)90058-0

[19] De Rick, A. and Vanheule, S. (2006) The Relationship between Perceived Parenting, Adult Attachment Style and Alexithymia in Alcoholic Inpatients. Addictive Behaviors, 31, 1265-1270. http://dx.doi.org/10.1016/j.addbeh.2005.08.010

[20] deTimary, P., Luts, A., Hers, D. and Luminet, O. (2008) Absolute and Relative Stability of Alexithymia in Alcoholic Inpatients Undergoing Alcohol Withdrawal: Relationship to Depression and Anxiety. Psychiatry Research, 157, 105113. http://dx.doi.org/10.1016/j.psychres.2006.12.008

[21] Thorberg, F.A., Young, R.M., Sullivan, K.A. and Lyvers, M. (2009) Alexithymia and Alcohol Use Disorders: A Critical Review. Addictive Behaviors, 34, 237-245. http://dx.doi.org/10.1016/j.addbeh.2008.10.016

[22] Joukamaa, M., Taanila, A., Miettunen, J., Karvonen, J.T., Koskinen, M. and Veijola, J. (2007) Epidemiology of Alexithymia among Adolescents. Journal of Psychosomatic Research, 63, 373-376. http://dx.doi.org/10.1016/j.jpsychores.2007.01.018

[23] Sakkinen, P., Kaltiala-Heino, R., Ranta, K., Haataja, R. and Joukamaa, M. (2007) Psychometric Properties of the 20-Item Toronto Alexithymia Scale and Prevalence of Alexithymia in a Finnish Adolescent Population. Psychosomatics, 48, 154-161. http://dx.doi.org/10.1176/appi.psy.48.2.154

[24] Honkalampi, K., Tolmunen, T., Hintikka, J., Rissanen, M.L., Kylmä, J. and Laukkanen, E. (2009) The Prevalence of Alexithymia and Its Relationship with Youth Self-Report Problem Scales among Finnish Adolescents. Comprehensive Psychiatry, 50, 263-268. http://dx.doi.org/10.1016/j.comppsych.2008.08.007

[25] Gatta, M., Dal Zotto, L., Schiff, S., Svanellini, L., Lai, J., Salis, M., et al. (2012) Alcohol Abuse and Psychopathology in Adolescence. Giornale di Neuropsichiatria Dell'età Evolutiva, 32, 197-203.

[26] Gatta, M., Cadevini, C., Svanellini, L., Aste, G., Penzo, M., Montagnese, S., Schiff, S., Battistella, P.A. and Gatta, A. (2014) Psycho-Behavioral Vulnerability of Adolescent Binge Drinkers. Prevention \& Research (in press).

[27] Gatta, M., Svanellini, L., Seminati, A., Penzo, M., Spoto, A. and Battistella, P.A. (2014) Recognition of Emotions and Drinking Expectancy: What Relation with Alcohol Misuse during Adolescence? Giornale di Neuropsichiatria Dell'età Evolutiva, 3 (in press)

[28] Gatta, M., Benanti, S., Svanellini, L., Penzo, M., Balottin, L. and Battistella, P.A. (2014) Alcohol and Emotions in Adolescence. Giornale di Neuropsichiatria Dell'età Evolutiva, 1, in Press.

[29] Gatta, M., Rotondo, G.C., Svanellini, L., Lai, J., Salis, M. and Ferruzza, E. (2014) Focus Groups as a Means for Preventing Adolescent Alcohol Consumption: Qualitative and Process Analysis. Journal of Groups in Addiction \& Recovery (in press).

[30] Trani, D.M., Tomassetti, N., Bonadies, M., Capozzi, F., De Gennaro, L., Presaghi, F. and Solano, F. (2009) Un questionario Italiano per l'alessitimia in età evolutiva: struttura fattoriale e attendibilità. Psicologia della Salute, 2, 131-143.

[31] Gallimberti, L., Chindamo, S., Buja, A., Forza, G., Tognazzo, F., Galasso, L., Vinelli, A. and Baldo, V. (2011) Underage Drinking on Saturday Nights, Sociodemographic and Environmental Risk Factors: A Cross-Sectional Study. Substance Abuse Treatment, Prevention and Policy, 6, 15.

[32] Achenbach, T.M. and Rescorla, L.A. (2001) Manual for the ASEBA School-Age Forms and Profiles. University of Vermont, Research Center for Children, Youth and Families, Burlington.

[33] Gallimberti, L. (2010) Il bere oscuro: Viaggio nei misteri dell’alcolismo. BUR Saggi, Milano.

[34] INRAN Istituto Nazionale di Ricerca per gli Alimenti e la Nutrizione (2003) Linee guida per una sana alimentazione italiana, Revisione, 7, 56-67.

[35] Rieffe, C., Oosterveld, P. and Terwogt, M.M. (2006) An Alexithymia Questionnaire for Children: Factorial and Concurrent Validation Results. Personality and Individual Differences, 40, 123-133. http://dx.doi.org/10.1016/j.paid.2005.05.013 
[36] Frigerio, A., Vanzin, L., Pastore, V., Nobile, M., Giorda, R., Marino, C., Molteni, M., Rucci, P., Ammaniti, M., Lucarelli, L., Lenti, C., Walder, M., Martinuzzi, A., Carlet, O., Muratori, F., Milone, A., Zuddas, A., Cavolina, P., Nardocci, F., Tullini, A., Morosini, P., Polidori, G. and De Girolamo, G. (2006) The Italian Preadolescent Project: Rationale and Methods. International Journal of Methods in Psychiatric Research, 15, 22-35. http://dx.doi.org/10.1002/mpr.25

[37] Ivanova, M.Y., Dobrean, A., Dopfner, M., Erol, N., Fombonne, E., Fonseca, A.C., Frigerio, A., Grietens, H., Hannesdottir, H., Kanbayashi, Y., Lambert, M., Achenbach, T.M., Larsson, B., Leung, P., Liu, X., Minaei, A., Mulatu, M.S., Novik, T.S., Oh, K.J., Roussos, A., Sawyer, M., Simsek, Z., Dumenci, L., Steinhausen, H.C., Metzke, C.W., Wolanczyk, T., Yang, H.J., Zilber, N., Zukauskiene, R., Verhulst, F.C., Rescorla, L.A., Almqvist, F., Weintraub, S., Bilenberg, N., Bird, H. and Chen, W.J. (2007) Testing the 8-Syndrome Structure of the Child Behavior Checklist in 30 Societies. Journal of Clinical Child and Adolescent Psychology, 36, 405-417. http://dx.doi.org/10.1080/15374410701444363

[38] Vanheusden, K., van Lenthe, F.J., Mulder, C.L., van der Ende, J., van de Mheen, D., Mackenbach, J.P. and Verhulstal, F.C. (2008) Patterns of Association between Alcohol Consumption and Internalizing and Externalizing Problems in Young Adults. Journal of Studies of Alcohol and Drugs, 69, 49-57.

[39] Frigerio, A., Rucci, P., Goodman, R., Ammaniti, M., Carlet, O., Cavolina, P., DeGirolamo, G., Lenti, C., Lucarelli, L., Mani, E., Martinuzzi, A., Micali, N., Milone, A., Morosini, P., Muratori, F., Nardocci, F., Pastore, V., Polidori, G., Tullini, A., Vanzin, L., Villa, L., Walder, M., Zuddas, A. and Molteni, M. (2009) Prevalence and Correlates of Mental Disorders among Adolescents in Italy: The PrISMA Study. European Child and Adolescent Psychiatry, 18, 217-226. http://dx.doi.org/10.1007/s00787-008-0720-x

[40] Levi, G., Di Biasi, S. and Tardiola, D. (2009) Problemi psicopatologici tra internalizzazione ed esternalizzazione: una ricerca per la prevenzione. In: Battistella, P.A., Gatta, M. and Mabilia, M., Eds., Aspetti psicopatologici e psichiatrici nella cura e nella tutela del bambino e dell'adolescente. Padova, Cleup, 29-40.

[41] Roberts, R.E., Attkisson, C.C. and Rosenblatt, A. (1998) Prevalence of Psychopathology among Children and Adolescents. American Journal of Psychiatry, 155, 715-725.

[42] Crijen, A.A., Achenbach, T.M. and Verhulst, F.C. (1997) Comparisons of Problems Reported by Parents of Children in 12 Cultures: Total Problems, Externalizing and Internalizing. Journal of American Academy of Child and Adolescents Psychiatry, 36, 1269-1277. http://dx.doi.org/10.1097/00004583-199709000-00020

[43] Clark, D.B., Vanyukov, M. and Cornelius, J. (2002) Childhood Antisocial Behavior and Adolescent Alcohol Use Disorders. Alcohol Research and Health, 26, 109-115.

[44] Brook, J.S., Whiteman, M., Finch, S. and Cohen, P. (1995) Aggression, Intrapsychic Distress, and Drug Use: Antecedent and Intervening Processes. Journal of the American Academy of Child and Adolescent Psychiatry, 34, $1076-1084$. http://dx.doi.org/10.1097/00004583-199508000-00018

[45] Jones, S.P. and Heaven, P.C. (1998) Psychosocial Correlates of Adolescent Drug-Taking Behavior. Journal of Adolescence, 21, 127-134. http://dx.doi.org/10.1006/jado.1997.0136

[46] Colder, C.R. and Chassin, L.C. (1997) Affectivity and Impulsivity: Temperament Risk for Adolescent Alcohol Involvement. Psychology of Addictive Behaviors, 11, 83-97. http://dx.doi.org/10.1037/0893-164X.11.2.83

[47] Colder, C.R. and O’Connor, R. (2001) Attention Biases and Disinhibited Behavior as Predictors of Alcohol Use and Enhancement Reasons for Drinking. Psychology of Addictive Behaviors, 16, 325-332. http://dx.doi.org/10.1037/0893-164X.16.4.325

[48] Bukstein, O.G., Brent, D.A. and Kaminer, Y. (1989) Comorbidity of Substance Abuse and Other Psychiatric Disorders in Adolescents. American Journal of Psychiatry, 146, 1131-1141.

[49] Lynskey, M.T. and Fergusson, D.M. (1995) Childhood Conduct Problems, Attention Deficit Behaviors, and Adolescent Alcohol, Tobacco, and Illicit Drug Abuse. Journal of Abnormal Child Psychology, 23, 281-302. http://dx.doi.org/10.1007/BF01447558

[50] Clark, D.B. and Bukstein, O.G. (1998) Psychopathology in Adolescents Alcohol Abuse and Dependence. Alcohol Health and Research World, 22, 117-121.

[51] Guo, J., Hawkins, J.D., Hill, K.G. and Abbott, R.D. (2001) Childhood and Adolescent Predictors of Alcohol Abuse and Dependence in Young Adulthood. Journal of Studies of Alcohol and Drugs, 62, 754-762.

[52] Young, R., Connor, J.P., Ricciardelli, L.A. and Saunders, J.B. (2006) The Role of Alcohol Expectancy and Drinking Refusal Self-Efficacy Beliefs in University Student Drinking. Alcohol and Alcoholism, 41, 70-75. http://dx.doi.org/10.1093/alcalc/agh237

[53] Hunt, J. and Eisenberg, D. (2010) Mental Health Problems and Help-Seeking Behavior among College Students. Journal of Adolescent Health, 46, 3-10. http://dx.doi.org/10.1016/j.jadohealth.2009.08.008

[54] Brady, K.T., Tolliver, B.K. and Verduin, M.L. (2001) Alcohol Use and Anxiety: Diagnostic and Management Issues. 
American Journal of Psychiatry, 164, 217-221. http://dx.doi.org/10.1176/appi.ajp.164.2.217

[55] Zucker, R.A., Wong, M.M., Puttler, L.I. and Fitzgerald, H.E. (2003) Resilience and Vulnerability among Sons of Alcoholics: Relationship to Developmental Outcomes between Early Childhood and Adolescence. In: Luthar, S.S., Ed., Resilience and Vulnerability: Adaptation in the Context of Childhood Adversities, Cambridge University Press, New York, 76-103.

[56] Ziolkowski, M., Gruss, T. and Rybakowki, J.K. (1995) Does Alexithymia in Male Alcoholics Constitute a Negative Factor for Maintaining Abstinence? Psychotherapy and Psychosomatics, 63, 169-173. http://dx.doi.org/10.1159/000288955

[57] Cleland, C., Magura, S., Foote, J., Rosenblum, A. and Kosanke, N. (2005) Psychometric Properties of the Toronto Alexithymia Scale (TAS-20) for Substance Users. Journal of Psychosomatic Research, 58, 299-306. http://dx.doi.org/10.1016/j.jpsychores.2004.11.002

[58] Martinotti, G., Hatzigiakoumis, D.S. and Janiri, L. (2010) Correlazioni tra alessitimia, alcolismo, disturbo da uso di sostanze e dipendenze comportamentali. Dipendenze Patologiche, 1, 25-36.

[59] Goldberg, J.H., Halpern-Felsher, B.L. and Millstein, S.G. (2002) Beyond Invulnerability: The Importance of Benefits in Adolescents' Decision to Drink Alcohol. Health Psychology, 21, 477-484. http://dx.doi.org/10.1037/0278-6133.21.5.477 